

Artigo de Revisão

\title{
Lesões Associadas à má Adaptação e má Higienização da Prótese Total
}

\author{
Maria Gabriela Farias Trindade ${ }^{1}$, Mirella Chaves de Oliveira ${ }^{2}$, \\ Jônatas Pereira do Prado ${ }^{3}$ Larissa Ledo Pereira Santana ${ }^{4}$
}

\begin{abstract}
Resumo: A prótese dentária tem como objetivo a reabilitação oral de dentes ausentes, possibilitando o desempenho e manutenção de suas funções. A mucosa oral está exposta ao desenvolvimento de diversas patologias, tais como estomatites protéticas, queilite angular, hiperplasias inflamatórias e úlceras traumáticas. Muitas dessas podem estar associadas ao uso das próteses mal adaptadas ou não higienizadas pelo paciente, devido, principalmente, a uma orientação inadequada do dentista. O presente trabalho tem como propósito apresentar as lesões causadas por má adaptação das próteses totais e pela deficiência de higienização por parte do paciente, alertando os profissionais da área odontológica e os usuários de próteses totais sobre tais problemas futuros, por meio da revisão da literatura. Os artigos a serem usados neste trabalho foram aqueles disponíveis nas plataformas de dados online: SCIELO e Revodonto, nos idiomas português, inglês e espanhol selecionados no ano de publicação 2008 a 2018. Foram selecionados 25 artigos que se encaixaram nos critérios de inclusão e exclusão deste trabalho. Conclui-se que estas lesões podem ser evitadas com a correta confecção da Prótese Total, um ajuste adequado na cavidade, orientação de higienização e realização de controles periódicos com o objetivo de não comprometer a mucosa bucal e prejudicar a mastigação.
\end{abstract}

Palavras-chave: Patologia Bucal. Iatrogenia. Prótese Total.

\section{Lesions associated with Maladaptation and poor Hygiene of Dentures}

\begin{abstract}
The dental prosthesis is used for the oral rehabilitation of missing teeth, enabling the performance and maintenance of their functions. The oral mucosa is exposed to the development of several pathologies, such as prosthetic stomatitis, angular cheilitis, inflammatory hyperplasias and traumatic ulcers. Many of these may be associated with the use of dentures that are poorly adapted or not sanitized by the patient, mainly due to inadequate dentist orientation. The purpose of this study was to present the lesions caused by maladaptation of dentures and by the patient's hygiene deficiency, alerting dental professionals and users of dentures of such future problems, through a review of the literature. The articles used in this project were those available on the online database platforms SCIELO and Revodonto, in the Portuguese, English and Spanish languages selected by the year of publication from 2008 to 2018. Twenty-five articles were selected which fit the inclusion and exclusion criteria of this project. It was concluded that these lesions can be avoided with the correct preparation of the dentures, an adequate fit into the oral cavity, hygiene orientation and periodic controls with the purpose of not jeopardizing the oral mucosa nor impair chewing.
\end{abstract}

Keywords: Oral Pathology. Iatrogeny. Dentures.

\footnotetext{
${ }^{1}$ Faculdade Independente do Nordeste - FAINOR. Contato: fariastrindadegabi@gmail.com.

${ }^{2}$ Graduanda do curso de Odontologia pela Faculdade Independente do Nordeste - FAINOR.

${ }^{3}$ Graduando de Odontologia na Faculdade Independente do Nordeste- FAINOR. Cursa Aperfeiçoamento em Cirurgia Bucal Avançada.

${ }^{4}$ Faculdade Independente do Nordeste - FAINOR.
}

956 Id on Line Rev. Mult. Psic. V.12, N. 42, p. 956-968, 2018 - ISSN 1981-1179
Edição eletrônica em http://idonline.emnuvens.com.br/id 


\section{Introdução}

A etiologia da perda dentária abrange vários fatores, porém suas principais causas são a cárie e a doença periodontal. Pode estar associado também às patologias sistêmicas, traumas, hábitos do paciente, como o tabaco e anomalias como agenesias que podem ser unitárias a totais (anodontia) ${ }^{1}$.

Uma das soluções de tratamento para a perda dentária é a prótese, que tem como objetivo a reabilitação oral de zonas desdentadas podendo ser fixas ou removíveis, parciais ou totais, cada uma com suas vantagens e desvantagens bastante conhecidas ${ }^{2}$.

O principal procedimento a ser realizado antes do planejamento do tratamento é o exame clínico e radiográfico da cavidade oral ${ }^{3}$. O dentista deve se atentar a diversos fatores ao planejar e confeccionar este dispositivo oral, dentre os quais estão à funcionalidade da articulação temporomandibular, tonicidade da musculatura, condições de higienização, distribuição das forças mastigatórias, condições oclusais, condições sistêmicas do paciente, entre outros. Este tratamento não descarta a chance de que novos problemas possam ocorrer sobre os elementos biológicos e protéticos envolvidos ${ }^{4}$.

Fatores como má adaptação da prótese sobre o rebordo e falta de higienização podem causar lesões na cavidade oral ${ }^{2}$. Além disso, o uso frequente, de dia e a noite também pode favorecer o surgimento de lesões na mucosa alveolar do paciente ${ }^{5}$. Dentre as lesões mais citadas estão estomatite protética, queilite angular, hiperplasia inflamatória, candidíase e ulceras traumática. Este dispositivo oral causa um desequilíbrio na microbiota local, levando a modificações na cavidade, pois a presença de materiais porosos, a diminuição de superfícies dentárias e associação ao envelhecimento e suas consequências levam à necessidade de adaptação do usuário e do seu próprio organismo ${ }^{6}$. A maioria dos portadores de Próteses Totais (PT) são idosos, alguns destes apresentam uma condição de higiene oral precária em decorrência das dificuldades motoras, além de serem mais propensos às infecções devido às patologias sistêmicas ${ }^{7}$.

Assim, o presente trabalho tem como objetivo apresentar, por meio da revisão de literatura, as lesões causadas por má adaptação das PT e pela deficiência de higienização por parte do paciente, alertando os profissionais da área odontológica e os pacientes sobre esses possíveis problemas futuros. 


\section{Metodologia}

Para realização do trabalho foram buscados artigos científicos, no período de março a outubro de 2018, através das plataformas de dados online: Google acadêmico, SCIELO e Revodonto, utilizando os seguintes descritores: prótese total, lesões orais, má adaptação, má higienização, métodos de higienização, queilite angular, candidíase oral, estomatite protética e hiperplasia inflamatória. Os artigos a serem usados neste trabalho são aqueles publicados disponíveis na íntegra, nos idiomas português, inglês, espanhol e selecionado conforme o ano de publicação - 2007 a 2018. Foram selecionados 25 artigos que se encaixaram nos critérios de inclusão e exclusão deste trabalho.

\section{Revisão de Literatura}

\section{Estomatites Protéticas}

Entre as principais lesões resultantes do uso da PT a mais predominante é a estomatite protética. Encontra-se na mucosa oral dos usuários de prótese total ou parcial removíveis. Sua etiologia é multifatorial e estão relacionadas a problemas de saúde geral do indivíduo, como deficiências nutricionais, diabetes, xerostomia, imunossupressão, fatores locais como placa bacteriana e presença de fungos e fatores mecânicos. Esses fatores associado à má adaptação e má higienização da PT contribui para que aconteçam alguns processos infecciosos por microrganismos ${ }^{8}$.

Estas alterações caracterizam-se por edema, hiperemia, seguido algumas vezes por petéquias hemorrágicas. $\mathrm{O}$ processo inflamatório varia de moderada ou intensa, e raramente o processo é sintomático 9 .

Estudos relatam que apesar do tecido apresentar-se inflamado e hiperêmico, esta lesão geralmente é assintomática, e por isso, passam despercebidas pelos pacientes, sendo notado durante exame bucal de rotina. A mucosa pode, porém, apresentar-se hemorrágica e o paciente pode sentir prurido, queimação, sintomatologia dolorosa, sabor desagradável, além de apresentar halitose e xerostomia ${ }^{10}$. 
No intuito de permitir uma melhor análise acerca da lesão, criou-se uma classificação de acordo os aspectos clínicos, especificando em três grupos: hiperemia puntiforme, hiperemia difusa e hiperemia granular ${ }^{11}$.

Hiperemia puntiforme (classe I) - Conhecida como hiperemia dos ductos de glândulas salivares palatinas menores; caracterizando aspecto eritematoso puntiforme, em áreas dispersas ou pequenas áreas localizadas no palato ${ }^{11}$;

Hiperemia difusa (classe II) - Citado por muitos autores como o tipo mais frequente. Com característica clinica de mucosa lisa e atrófica, com aspecto eritematoso em toda região sob a prótese ${ }^{11}$;

Hiperemia granular (classe III) - Geralmente associada à câmara de sucção, acometendo a região central do palato com aspecto clínico nodular e rugosa da mucosa ${ }^{11}$.

De acordo pesquisa está lesão acomete mais mulheres, no entanto, não há nenhuma diferença entre os sexos, segundo autores ${ }^{13}$.

Normalmente encontra-se esta lesão na região da mucosa jugal, a orofaringe, o fundode-saco vestibular e as partes laterais do dorso lingual, destacaram ainda o palato como um das regiões mais constantes associados à mucosa bucal, o palato e a língua como os locais de favoritismo, e a gengiva e o assoalho bucal também foram citados ${ }^{14}$.

O diagnóstico é realizado por meio do exame clínico, notando presença de alterações de cor, textura, sintomatologia, tipo, estado e função da prótese, e o nível de higiene, podendo associar a exames complementares citológicos e histopatológicos ${ }^{12}$.

As características histopatológicas consistem em: epitélio pavimentoso estratificado, que envolve tecido conjuntivo fibroso hiperplásico, com número elevado de fibras colágenas, exibindo também alto grau de células inflamatórias crônicas e quantidade variável de vasos sanguíneos, podendo o epitélio ser ceratinizado ou não ${ }^{15}$.

O tratamento desta lesão consiste em condutas de higiene bucal e da prótese, com remoção da prótese durante a noite, identificação e correção de fatores predisponentes, reembasamento ou confecção de nova prótese e terapia antifúngica quando associada à candidose bucal. Além desses procedimentos, podem associar-se a desinfecção da prótese durante a noite com soluções químicas, como a clorexidina e hipoclorito de sódio ${ }^{10}$. 


\section{Queilite Angular}

A queilite angular é uma lesão frequentemente encontrada em pacientes idosos com dimensão vertical reduzida, o que facilita o acúmulo de saliva nas comissuras labiais, retendo umidade e permitindo a infecção por Candida albicans, sendo caracterizada por eritema, fissuração e descamação ${ }^{14}$. Alguns autores acreditam que os usuários de próteses orais (próteses e aparelhos) são mais predisponentes a ter Candida espécies colonizadas na sua flora oral ${ }^{15}$.

A etiologia desta lesão, geralmente, está relacionada à: agentes infecciosos (Estreptococos, Estafilococos e Candida albicans); doenças dermatológicas (dermatite atópica, envolvendo a face e dermatite seborréica); deficiência nutricional (riboflavina, folato e ferro), imunodeficiência (HIV, diabetes mellitus, câncer, transplante), aumento no nível salivar e fatores mecânicos provocando a perda da dimensão vertical de oclusão, com queda do lábio superior sobre o inferior, na altura do ângulo da boca, como ocorre no processo normal de envelhecimento, no prognatismo, na ausência de dentes ou com o uso de próteses mal adaptadas. Também pode ocorrer se, após extrações, o paciente não é provido de uma prótese adequada ou se são feitas restaurações sem levar em conta a necessidade de proteger a anatomia da fenda labial ${ }^{16}$.

Para um correto diagnostico é necessário o exame clínico, juntamente com a história do caso sendo relatado de forma correta. Uma história detalhada, incluindo o estado da saúde bucal, práticas de higiene oral, e ocupação deve ser levada em conta. É fundamental questionar os pacientes sobre doenças médicas, como anemia e doenças de imunodeficiência; tabagismo; o uso de tabaco de mascar; consumo de álcool; desordens cutâneas (dermatite atópica, psoríase, líquen plano); desordens alérgicas (asma, eczema); e o uso de qualquer medicação sistêmica ${ }^{15}$.

Apesar da maioria dos casos serem facilmente diagnosticado, algumas lesões assemelham-se outras situações comuns. Por exemplo, o herpes labial e líquen plano erosivo podem assimilar a queilite angular, pois ambos podem afetar os ângulos da boca. Este é um dos motivos que torna fundamental uma história detalhada das lesões, relatando a duração, a periodicidade, o tratamento anterior, e recorrência se houver. Ao realizar o exame clínico, é fundamental procurar por sinais de crostas, vesiculação, rachaduras, atrofia, supuração e ulceração. Outro exame de tal importância é um exame intraoral, para procurar qualquer 
desordem dos dentes ou dentaduras, gengiva e mucosa oral. Após inspeção clínica e a extensão da doença é determinada, os pacientes podem ser classificados em 3 categorias gerais: ligeira, moderado e severa ${ }^{17}$.

Os aspectos clínicos da QA são sutis, no entanto, podem causar desconforto e inconveniência, fazendo com que o diagnóstico precoce dessa lesão, seja fundamental para diminuir os riscos de desenvolvimento do câncer ${ }^{18}$.

As características histopatológicas da QA podem por atrofia do epitélio escamoso estratificado, com frequente produção de queratina. A hiperqueratose, paraqueratose e acantose são aspectos comuns das queilites actínicas. São notavéis áreas de hiperplasia, atrofia e graus variados de atipia que vão desde uma alteração discreta a carcinoma in situ e até invasivo ${ }^{19}$.

A princípio, no tratamento, inicia-se com a terapia medicamentosa nos locais das lesões, alertando ao paciente que evite alimentos e bebidas ácidas que irritam o local. Dificilmente são necessários tratamentos em longo prazo, por via oral ou até cirúrgico. No tratamento da QA é fundamental a correção dos fatores causais, por exemplo, adequação de próteses dentária e correção de deficiência nutritiva, terapia da doença de base, assim como aplicação de antimicóticos e antibióticos tópicos por tempo prolongado. A profilaxia da QA é de extrema importância, mantendo a higiene e desinfecção adequadas de próteses dentárias, fontes potenciais de contaminação, prevenindo as recidivas. Alguns casos é preciso a realização de cirurgia plástica para levantar os ângulos da boca, evitando-se assim o acumulo de saliva nas comissuras $^{20}$.

\section{Hiperplasia Fibrosa}

A hiperplasia fibrosa inflamatória, também nomeada como epúlide fissurada, epúlide causada por dentadura ou ainda tumor de dentadura, é uma lesão constantemente encontrada na clínica odontológica. Está lesão é formada por uma massa tumoral de tecido conjuntivo fibroso, provocada por traumatismo da borda da PT ou prótese parcial removível com má adaptação ${ }^{21}$.

Por mais que a hiperplasia fibrosa inflamatória esteja repetidamente relacionada ao uso de próteses dentárias mal adaptadas, esta lesão pode apresentar ainda outros fatores etiológicos

961 Id on Line Rev. Mult. Psic. V.12, N. 42, p. 956-968, 2018 - ISSN 1981-1179 Edição eletrônica em http://idonline.emnuvens.com.br/id 
como: diastema, má higienização, aresta de dentes cortantes, manobras iatrogênicas profissionais, além de estar associada à prótese inadequada associada a infecções fúngicas ${ }^{22}$.

As características clinicas são como uma lesão de crescimento lento e assintomático e sua consistência variando entre firme e flácida à palpação, na maioria dos casos são de base séssil e raramente pediculada, pode ser exofítica ou uma elevação bem definida, superfície lisa ocasionalmente apresenta ulceração, pode ser pequena ou atingir centímetros de diâmetros, a coloração varia da semelhança da cor da mucosa adjacente a eritematoso. Frequentemente afeta a face vestibular da mucosa alveolar, no entanto, pode desenvolver - se nas faces palatina ou lingual ${ }^{22}$.

Está lesão é mais frequente em adultos, por estarem associada ao uso de próteses com adaptação inadequada, acometendo, igualmente, a região da maxila e mandíbula. A região anterior é mais afetada, acometendo principalmente mulheres. Proliferação de tecido que aparece no palato é causada devido à irritação mecânica e, ao acúmulo de detritos alimentares infectados por microrganismos ${ }^{23}$.

A característica histológica que mais se destaca é a hiperplasia de tecido conjuntivo fibroso. Geralmente o epitélio de recobrimento é hiperparaqueratótico, com hiperplasia irregular das papilas. Raramente, o epitélio apresenta hiperplasia papilar inflamatória ou epiteliomatosa (pseudocarcinomatosa). São comuns áreas focais de ulceração, principalmente entre as pregas; infiltrado inflamatório crônico variável, podendo apresentar eosinófilos ou folículos linfóides, que complementam o quadro histológico ${ }^{21}$.

O tratamento pode ser realizado de forma conservador ou cirúrgico, a depender da gravidade do dano tecidual e a quantidade de tecido afetado. Em casos que houve evolução tecidual considerável e longo prazo a opção mais adequada é a excisão cirúrgica do tecido hiperplásico com uma pequena margem de segurança, tendo cuidado com áreas anatômicas que precisam ser mantido, para impedir a intervenção do tecido com a retenção da prótese ou, caso seja necessário, realizar uma cirurgia combinados para aumentar a esta profundidade ${ }^{24}$. 


\section{Úlcera Traumática}

A úlcera traumática da mucosa bucal ocorre devido algum trauma, podendo estar caracterizada por mordida da mucosa, irritação por prótese removível, lesão por escova dental, exposição da mucosa à cárie dentária ou presença de qualquer outro irritante externo, podendo evoluir para malignidade. A estomatite de contato é uma forma de hipersensibilidade retardada que poderia ocorrer em qualquer lugar da mucosa bucal, produzindo eritemas característicos no local do contato ${ }^{16}$.

Esta lesão é frequentemente encontrada na mucosa bucal, a qual apresenta uma etiologia multifatorial, no entanto, sua principal causa seja consequente de iatrogênias do profissional nos usuários da prótese total mucossuportada. A língua, a mucosa jugal e o lábio inferior são as regiões mais suscetíveis, no entanto, outros sítios podem também serem afetados, dependendo da etiologia. Caracteriza-se por uma área central de ulceração recoberta ou não por membrana fibrinopurulenta circundada por halo eritematoso. Geralmente o paciente relata sintomatologia dolorosa, principalmente durante a ingestão de alimentos ${ }^{24}$.

Geralmente podem ser de natureza aguda ou crônica, dependendo do tempo de uração e da sintomatologia apresentada. E aparece em maior volume entre o primeiro e o segundo ano de uso da prótese. Porém, é bastante comum seu aparecimento logo após a instalação ou no período de adaptação. Este acontecimento está vinculado também às moldagens incorretas realizadas com moldeiras que apresentam sobre-extensão de borda e que acabam por comprimir áreas do fornix do vestíbulo bucal gerando feridas com sintomas dolorosos intensos ${ }^{5}$.

As úlceras orais podem ainda ser classificadas em primárias e secundárias. Uma úlcera é considerada primária quando a lesão não é precedida por outra lesão prévia. As úlceras são designadas secundárias quando se originam através da rutura de uma vesícula ou bolha. Neste sentido, as úlceras presentes na cavidade oral de pacientes que possuem patologias vesiculobolhosas ou ulceração devida a infeção por herpes simples são classificadas como úlceras secundárias $^{25}$.

O tratamento consiste na remoção do fator causal e prescrição medicamentosa (corticóides e antinflamatórios tópicos) que também podem ser adotadas para alívio da sintomatologia dolorosa. Vale ainda destacar que quando o fator etiológico desta lesão for uma prótese mal adaptada, o tratamento deve ser associado com medicamentos analgésicos e 
correção ou substituição do aparelho protético, seja na sua base ou na região dos dentes artificiais. Depois de corrigir a prótese, realizando um alívio nas zonas que estão provocando trauma, a úlcera deve cicatrizar em duas semanas. Se tal fato não ocorrer, pode ser necessária a realização de uma biópsia incisional. Para prevenir a ocorrência da úlcera deve-se atentar, no ajuste da oclusão, de forma a distribuir a carga mastigatória de modo uniforme $e^{24,5}$.

\section{Discussão}

Apesar dos avanços da Odontologia, a perda dentária consiste, numa realidade dentro da população brasileira. Esse fato pode estar associado, ao aumento da expectativa de vida. Sendo a prótese um artificio relevante no processo de reabilitação desses indivíduos desdentados ${ }^{4,5,8}$

A prótese total deve cumprir seu papel estético e funcional, reabilitando o equilíbrio do sistema estomatognático. É sabido que mesmo fazendo uso de todas as técnicas clínicas e laboratoriais extremamente corretas, a mucosa oral sofre agressões por meio dessa peça. Tal fato proporciona ao tecido, em algumas situações, lesões ulceradas, infecciosas, neoplásicas, inflamatórias e hiperplásicas ${ }^{3,5,9,24}$

Frente ao grande número de indivíduos desdentados que fazem uso da prótese, seja esta total ou parcial, há um espectro significativo de lesões que merecem destaque e serem analisados. Estas lesões se apresentam, na maioria dos casos, em usuários de próteses totais (PT). Dentre elas, há maior prevalência de: estomatite, queilite angular, hiperplasia inflamatória e úlcera traumática. Um estudo realizado em 2008 no Brasil evidenciou que a estomatite protética apresenta uma maior prevalência, quando comparadas às outras 3 lesões abordadas neste trabalho ${ }^{3,4,16}$.

Estudiosos afirmam que a estomatite está entre as patologias mais decorrentes devidas uso de próteses dentárias. Está se caracteriza por ser uma lesão eritematosa, algumas vezes acompanhada de petéquias, que normalmente aparecem na região chapeável da prótese, principalmente quando estas se encontram mal adaptadas e em pacientes idosos, provavelmente 
devido á dificuldade de higienização. Outros autores, afirmam ainda que a sua etiologia pode ser multifatorial, uma vez que esta tem se demonstrado altamente variável ${ }^{8,9,10,16}$.

O diagnóstico da estomatite protética deve ser o mais precoce possível, haja vista que tal situação pode se tornar insuportável ao indivíduo, levando-o a rejeitar a prótese, além de prejudicar todo o sistema estomatognático. Este diagnóstico se baseia nos achados clínicos na mucosa oral. A partir daí o tratamento incluirá instruções de higiene oral e da prótese, reembasamento ou confecção de uma nova peça; ou até mesmo terapia antifúngica ${ }^{10,11,13}$.

Outra lesão não menos importante, é a queilite angular (QA). Mais prevalente naqueles indivíduos que possuem pregas da comissura labial profundas, que permite um acúmulo de saliva. Refere-se um processo inflamatório, localizado no canto da boca, que pode se localizar tanto uni como bilateralmente, e é caracterizado por edema, eritema, descamação, erosão e fissuras ${ }^{8}$.

Para alguns autores, a QA é diagnosticada apenas por um exame clínico eficaz, juntamente com a história clínica do paciente. Esses afirmam ainda que seu tratamento é fundamental na correção dos fatores desencadeantes, como terapia da doença de base ${ }^{17,18}$.

No mesmo estudo em que se destacou o grande índice de estomatite, a hiperplasia fibrosa inflamatória apresenta-se como a segunda lesão mais frequente nos portadores de próteses totais. Esta consiste, segundo alguns autores, em uma lesão benigna do tecido conjuntivo que ocorre nos rebordos maxilares e mandibulares decorrentes de traumas constantes na região $0^{3,16}$.

Frente a esta situação, estudiosos afirmam que o tratamento estabelecido dependerá da gravidade dos danos sobre os tecidos locais, além da quantidade de tecido afetado. Podendo ser tomada algumas medidas conservadoras, até intervenção cirúrgica afim de que o problema seja totalmente solucionado ${ }^{3,21,22,23}$.

A úlcera traumática é uma lesão com menos incidência quando comparada às outras abordadas neste trabalho, entretanto a mesma merece destaque, por ser uma lesão, considerada por alguns estudiosos, extremamente dolorosa. Esta alteração ocorre principalmente em próteses que não tenham sido adaptadas ao rebordo da mucosa oral, por este fato está frequentemente presente nos sulcos vestibulares ${ }^{5,8,24}$.

Esta alteração pode se tornar mais frequente por estar em alguns casos associada à evolução da hiperplasia inflamatória. Apesar dessa associação, a úlcera tem etiologia

965 Id on Line Rev. Mult. Psic. V.12, N. 42, p. 956-968, 2018 - ISSN 1981-1179 Edição eletrônica em http://idonline.emnuvens.com.br/id 
multifatorial, o que interfere no processo de diagnóstico e tratamento. Segundo os pesquisadores, por ser muitas vezes associada à prótese mal adaptada, o seu tratamento será a base de analgésicos e correção da prótese dentária presente ${ }^{5,8}$.

Entende-se como base na pesquisa realizada para este trabalho que existem diversas lesões que podem estar associadas ao uso de próteses totais, destacando-se as discutidas neste trabalho. Assim, o Cirurgião-Dentista (CD) deve ter conhecimento das mesmas. Para que se tenha um sucesso da PT e menos incidências de lesões provocadas pelo uso da mesma, faz-se necessário ter alguns cuidados durante sua confecção (1) e na sua higienização $(2)^{8}$.

Pinho; Muniz e Melo ${ }^{8}$ evidenciam que o papel fundamental está nas mãos do CD, pois o mesmo deve prestar atenção a todos os fatores essenciais para a confecção de uma PT, desde a avaliação intra e extra-oral até as instruções corretas passadas ao paciente quando da entrega da prótese. Outro fator importante se trata da higienização dessa peça. Esta deve ser feita de forma criteriosa, em razão de suas características anatômicas, assim como pelo fato de sua construção depender de um material com micro porosidades, que é a resina acrílica.

\section{Conclusões}

Infere-se que as próteses dentárias são de extrema importância para reabilitação oral dos pacientes. Tal dispositivo deve ser confeccionado corretamente e ser devidamente higienizado com o objetivo de não comprometer a mucosa bucal e prejudicar a mastigação. Conforme a literatura consultada grande parte das lesões orais associadas à prótese total é fomentada pela má adaptação e higienização deficiente do aparato protético.

Entre as principais lesões estão: estomatites protéticas, queilite angular, hiperplasias inflamatórias e úlceras traumáticas. Por isso, são fundamentais que o cirurgião-dentista realize de forma correta a confecção da PT, além de instruir seus pacientes quanto a sua higienização oral. 


\section{Referências}

1. Alves DLN. Candida spp. e Prótese Dentária Removível: Interacções de Relevância Clínica Revisão Bibliográfica [dissertação]. Porto: Universidade Fernando Pessoa - Faculdade de Ciências da Saúde, 2009.

2. Carli JP, Giaretta BM, Vieira RR, Linden MSS, Ghuzoni JS, Pereira JR. Lesões bucais relacionadas ao uso de próteses dentárias removíveis. Salusvita 2013; 32(1): 103-115.

3. Batista VES, Batista FRS, Pavan AJ, Matheus G, Silva MM. Hiperplasia fibrosa inflamatória ocasionada por prótese total desadaptada, relato de caso. Rev. Odontol. de Araçatuba 2013; 34(2): 70-72.

4. Paranhos VB, Rocha FS, Siqueira AL, Carvalho QA. Manifestações orais associadas ao uso de próteses totais [dissertação]. Uberlândia: Universidade Federal de Uberlândia, 2008.

5. Peixoto ANT, Peixoto GC, Alessandretti R. Relação entre o uso de prótese removível e úlcera traumática - revisão de literatura. J Oral Invest 2015; 4(1): 26-32.

6. Freire JCC, Nóbrega MTC, Freire SCP, Dias-Ribeiro E. Candidíase oral em usuários de próteses dentárias removíveis: fatores associados. Arch Health Invest 2017; 6(4): 159-261.

7. Eler KAS, Kaiser TF. Candidíase em pacientes portadores de prótese total [dissertação]. Porto Velho: Centro Universitário São Lucas, 2017.

8. Pinho LCF, Muniz SKC, Melo ITS. Principais lesões orais ocasionadas pela má higienização da prótese parcial removível e pela má higienização. Caderno de Cien. Biol. e da Saúde 2013; 1.

9. Oliveira RC, Brum SC, Oliveira RS, Goyatá FR. Aspectos clínicos relacionados à estomatite protética. International J.of Dent 2007; 6(2):51-4.

10. Arnoud RR, Soares MSM, Santos MGC, Santos RC. Estomatite protética: prevalência e correlação com idade e gênero. R Bras Ci Saúde 2012; 16(1):59-62.

11. Scalercio M, Valente T, Israel MS, Ramos ME. Estomatite protética versus candidíase: diagnóstico e tratamento. Rev Gaúcha de Odontol 2007; 55(4):395-8.

12. Silva UH, Araújo DL, Santana EB. Ocorrência de estomatite protética e queilite actínica diagnosticadas no centro de especialidades odontológicas da faculdade ASCES, Caruaru - PE. Odontol. Clín-Cient 2011; 10(1):79-83.

13. Gonzáles IJN, Gomez SMD, Capote EP, Rivero YC. Prevalence of subprosthesis stomatitis. Rev Arch Médico de Camagüey 2009; 13(1);

14. Barbosa MT, Neto OI, Rodrigues CRT, Laport LBR, Oliveira WS, Oliveira TBS. Lesões bucais provocadas pelo uso de próteses removíveis. Braz. J. of Sug. And Clinical Reserach 2018; 22(2):626. 
15. Falcão AFP, Lamberti PLR, Lorens FGL, Lacerda JA, Nascimento BC. Hiperplasia fibrosa inflamatória: relato de caso e revisão de literatura. $R$. Ci. méd. biol. 2009; 8(2):230-6.

16. Maciel SSSV, Souza RSV, Donato LMA, Albuquerque IGM, Donato LFA. Prevalência das lesões de tecidos moles causadas por próteses removíveis nos pacientes da Faculdade de Odontologia de Caruaru, PE, Brasil. Pesquisa Bras em Odontop e Clín Integrada 2008; 8(1):93-7.

17. Dermacase. Anhular cheilitis. Canadian Family Physician • Le Médecin de famille canadien 2007; 53:1022-3.

18. Vilela GR. Queilite actínica- revisão de literatura. [dissertação]. São Gonçalo do Sapucaí: Universidade Federal de Minas Gerais, 2011.

19. Araújo CP, Vidal MTA, Gurgel CAS, Ramos EAG, Barbosa Jr AA, Ramalho LMP, et al. Queilite actínica: um estudo de 35 casos com destaque para os aspectos morfológicos. Rev. Pós Grad. 2012; 19(1):21-7.

20. Almeida VGV, Melo GMS, Lima GA. Queilite angular: sinais, sintomas e tratamento. International J.of Dent 2007; 6(2):55-7.

21. Pedron IG, CarnavaTG, Utumi ER, Moreira LA, Jorge WA. Hiperplasia fibrosa causada por prótese: remoção cirúrgica com laser Nd:YAP. Rev Clín Pesq Odontol 2007; 3(1):51-6.

22. Souza LM. Hiperplasia fibrosa inflamatória ocasionada por prótese dentária mal adaptada [dissertação]. Porto Velho: centro de Ensino Faculdade São Lucas, 2016.

23. Carvalho FR, Voss F, Nascimento JA, Trazzi BFM, Esteves SRR, Rodrigues AC, et al. Hiperplasia fibrosa inflamatória - revista da literatura - relato de caso clínico cirúrgico. Rev. Odont. 2017; 17(4):290-8.

24. James, Barbosa JRA, Olate S. Indlammatory fibrous hyperplasia treated with a modified vestíbuloplastry: a case report. The J of Contemp Dental Pract 2008; 9(3):1-7.

25. Paiva TMM. Lesões Ulcerativas da Cavidade Oral e a Importância do Diagnóstico Diferencial Estudo Observacional. [dissertação]. Viseu: Universidade Católica Portuguesa, 2013.

\section{Como citar este artigo (Formato ABNT):}

TRINDADE, Maria Gabriela Farias; OLIVEIRA, Mirella Chaves de; PRADO, Jônatas Pereira do; SANTANA, Larissa Ledo Pereira. Lesões Associadas à má Adaptação e má Higienização da Prótese Total. Id on Line Rev.Mult. Psic., 2018, vol.12, n.42, p. 956-968. ISSN: 1981-1179.

Recebido: 25/10/2018;

Aceito: 26/10/2018 